\title{
Society for Pediatric Research 2014 Presidential Address: the test of our progress
}

\author{
Steven P. Miller ${ }^{1,2}$
}

\author{
"The test of our progress is not whether we add more to the \\ abundance of those who have much; it is whether we provide \\ enough for those who have too little."
}

-US President Franklin D. Roosevelt

n this era of unprecedented opportunity for science discovery to advance pediatric care and improve child health, the Society for Pediatric Research (SPR) serves to "foster the research and career development of investigators engaged in the health and well-being of children and youth" (1). As a society, it is important to acknowledge our members who have contributed their time and energy to work with the SPR to achieve this mission. My goal for this address is to encourage more of us to actively engage with the SPR. Many challenges to the future of child health researchers lie ahead, and the SPR needs your voice.

The most important lesson I learned in my years on the SPR Council is that the SPR is about our community, pediatric research, and ultimately about child health. The SPR now has a broad view of pediatrics that includes pediatricians, neurologists, geneticists, psychologists, rehabilitation scientists, nurses, epidemiologists, and health services and policy researchers. I believe that the most urgent issues facing the SPR are our brain drains: our nation's children and our young investigators.

In this review, I will first address the SPR's progress in growing from a focus of pediatric research to a more holistic focus of child health research. I will then address the critical issues of supporting child health researchers early in their career trajectory. While I use the developing brain as the context for my comments, I hope that you find the issues addressed equally relevant to your area of pediatric research as it is ultimately about the whole child.

In the six years that I served on the SPR Council, I observed a phenomenal shift toward an inclusive view of child health research that now engages nonpediatricians. The researchers represented by the SPR now include discovery scientists, translational and clinical scientists, and a growing cadre of health services investigators. This growth is evident in the SPR's leadership; our Council currently includes a neurologist and a psychologist. I will argue that if we truly want to impact health through research on the most effective scale possible, then this trend toward an inclusive child health research agenda should be fostered. I will make this case with the developing brain.

Nowhere is the importance of investing in pediatric research more apparent than in our understanding of the developing brain. The brain undergoes a remarkable period of development over the time we care for children, as shown on diagnostic magnetic resonance images obtained in a neonate born more than 3 months early (26 weeks of gestation), scanned at 2 weeks of age and again at term-equivalent age, 12 weeks later (Figure 1). The brain undergoes a similarly dramatic phase of development from the neonatal period through early childhood. The cerebral cortex matures from being relatively smooth in the preterm period to being fully sulcated and gyrated by term-equivalent age. At termequivalent age, myelin is now evident in the posterior limb of the internal capsule, where our voluntary motor pathways descend as the corticospinal tracts. By 8 years of age, the contrast between cortex and white matter is inversed as the brain is now fully myelinated (Figure 1). Most importantly, all of this development is occurring over the period that children regularly receive pediatric care. This impressive period of development is coupled with an exquisite vulnerability to injury, either directly by events such as stroke or trauma or indirectly by systemic conditions such as heart disease, kidney disease, or cancer and its treatment. There is also increasing recognition that this period of brain development is remarkably sensitive to social deprivation and the child's environment. With the transformative improvements we have seen in pediatric medicine, a major remaining challenge in the care of children is to ensure that the sickest of the sick develop as well as those who are healthy. As the SPR, we must also focus our attention on those who may be less "ill" but still face adversity.

I need to be certain that my comments suggest a growth for our society rather than a shift away from our focus on the need for discovery. Discovery research is foundational to all we do, and supporting our discovery researchers continues to be a thrust of the SPR. The importance of discovery is highlighted by brain research in that $90 \%$ of what we know about the brain we have learned in the past 15 years (2).

We are now in an era of unprecedented opportunities for science discovery with new potentials to transform child

\footnotetext{
'Department of Paediatrics, University of Toronto, Toronto, Ontario, Canada; ${ }^{2}$ Department of Paediatrics and the Centre for Brain \& Mental Health, The Hospital for Sick Children, Toronto, Ontario, Canada. Correspondence: Steven P. Miller (steven.miller@sickkids.ca) 


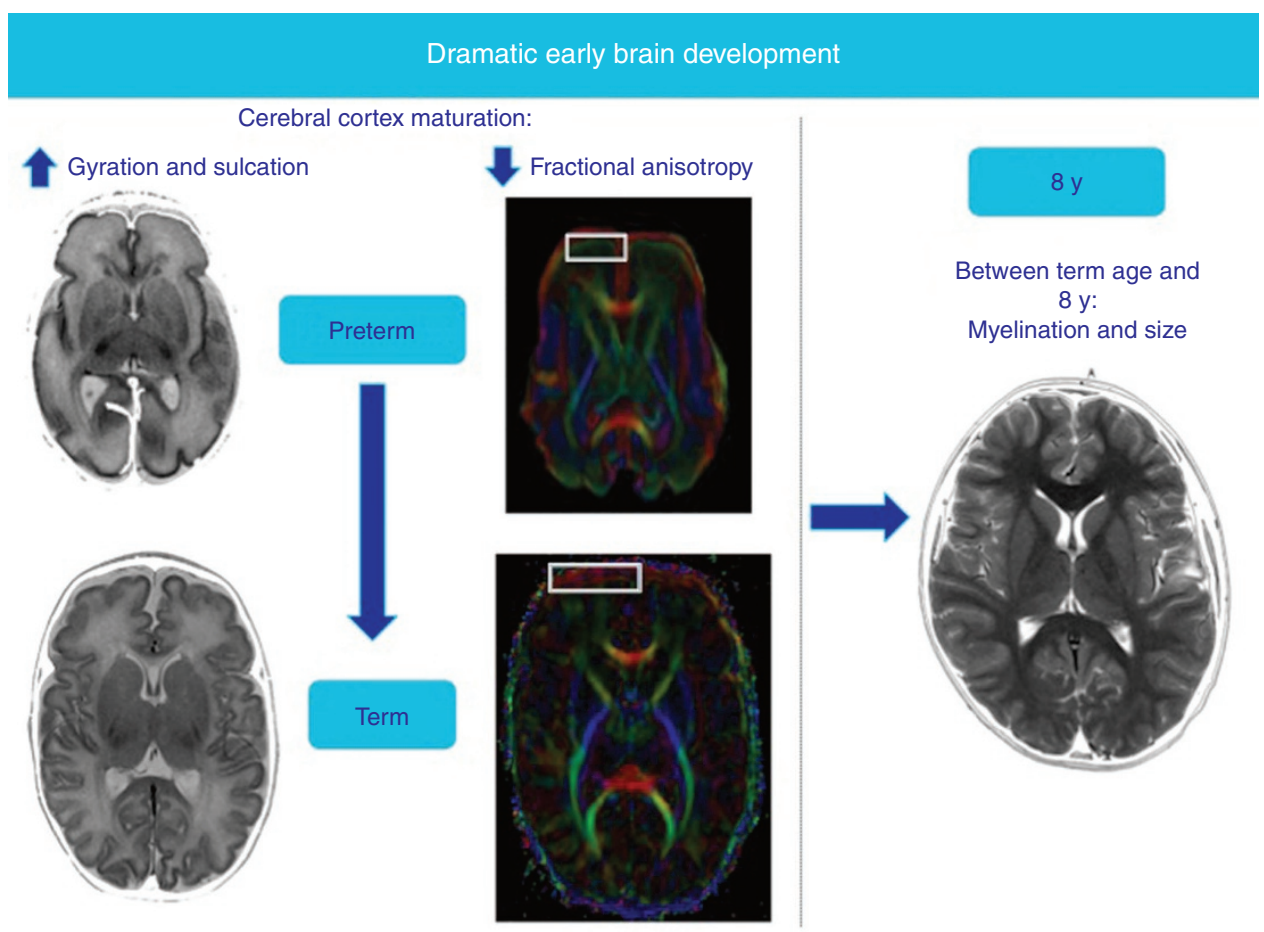

Figure 1. Dramatic early brain development illustrated with MRI images of a preterm neonate scanned at 28 weeks postmenstrual age and at 40 weeks postmenstrual age (term-equivalent), and a child at 8 years of age.

health, whether at the basic biochemical development of cells, genetics, epigenetics or systems biology. These discoveries are dependent on investigators, and we must support the pipeline of young child health investigators to ensure that this era continues. Enabled by new technology, including imaging, there is increasing translational clinical research at the interface of our subspecialties. As an example, the field of imaging the developing brain has advanced from diagnostic imaging toward quantitative imaging tools, such as diffusion tensor imaging that can now be used to infer the microstructure of the brain (Figure 1). Diffusion tensor imaging has been used widely to examine white matter development in newborns and children. Dr Robert McKinstry, a neuroradiologist, and colleagues at Washington University made the seminal observation that diffusion tensor imaging can also be used to examine early microstructural development of the cerebral cortex (Figure 1) (3). We recently observed that this incredible period of brain development occurs less robustly in preterm neonates who are not growing well through their period of neonatal intensive care (4). This offers the hope that advances in neonatology and nutrition science will serve as potent brain protection in the near future.

But what of actually "healing" the brain? With billions of neurons making trillions of connections, the brain could be thought of as a circuit with components at the macro-, micro-, and nanocircuitry levels. Macrocircuits, the long tracts in the brain, are analogous to the brain's information superhighways. Microcircuits, the neurons and glia in the brain, are analogous to our personal computers or handheld devices. Nanocircuits, the biochemical pathways of the cells, are analogous to chips and components such as transistors. The idea of healing the brain is no longer science fiction: with this circuit analogy, we can think of therapies at each of the levels of circuitry. At the macrocircuit level, deep brain stimulation initially introduced for the treatment of movement disorders is now being investigated for the treatment of mental health conditions such as depression and anorexia nervosa $(5,6)$. Cochlear implants remain an important example of brain prosthetics offering unprecedented hope for children with hearing loss (7). At the microcircuitry level, ongoing developments of drug and brain computer interfaces continue to advance toward healing brain microcircuitry. Finally, the possibility of repairing genes using new technologies such as clustered regularly interspaced short palindromic repeats may make healing the brain nanocircuitry a reality for our next generation of children (8).

Until these discoveries are ready to debut for clinical trials and applications, there is still much to be done to improve the outcomes of sick children. In her 2011 SPR President's address, Dr Maria Britto showed compelling data from the US Cystic Fibrosis Foundation. The foundation documented a dramatic increase in survival of children born with cystic fibrosis from 1994 to 2006-survival increased from 27.7 years in 1994 to 36.9 years in 2006. The dramatic increase in survival over this period has been attributed to the foundation's National Quality Initiative. These data, and many other outcomes studies, have increased the SPR's attention to embracing health services researchers. In addition to ongoing discovery, we must continue to strive to "close the gap between what we know and what we do" (9).

Public health strategies targeting women of childbearing age and children were implemented successfully throughout the 1990 s and were enabled by research (10). These interventions 
included tobacco control efforts, expanded childhood immunization, universal HIV testing in pregnant women, "back to sleep" public education for prevention of sudden infant death syndrome, and mandatory food fortification with folic acid, among others. Notably, all women and children do not share the benefits of these interventions equally. Dr Arjumand Siddiqi, an epidemiologist at the University of Toronto, proposes the hypothesis that the primary reason inequalities are larger in some places than others is because different places have different societal conditions, in particular different health, education, and social welfare policies $(11,12)$. In the United States, Canada, and countless other countries, children who do not share the good outcomes resulting from public health strategies and continue to face adversity as children have health risks that carry forward through to their adulthood.

As pediatricians, we recognize the importance of the social context in a child's development. Even with this recognition, the difference in a child's vocabulary by his or her socioeconomic status is striking. Drs Betty Hart and Todd Risley's striking data show that by 3 years of age, children in high income groups have a cumulative vocabulary of $\sim 1,200$ words, those in middle income groups have a vocabulary of just above 600 words, and those in low income groups have vocabularies of fewer than 600 words (13). Studies show a substantial relationship between vocabulary sizes in first grade with reading comprehension later in childhood, an outcome critical for future academic achievement and employment (14). As education determines a nation's health, it is critical to examine what determines educational outcomes. A recent examination of the effect of national policies on educational outcomes reveals rather surprisingly that it is income inequality, rather than direct spending on education and overall national economic prosperity, that is the key driver for educational outcomes (15). In addition to lost opportunities related to income inequality, the cost of inaction to promote early child health is staggering. In Canada, the cost of adolescents who do not complete school ("early school leavers") is estimated by the Canadian Council on Learning to be $\$ 2.6$ billion (Canadian dollars) annually for each cohort of early school leavers. This amounts to a $\$ 17.6$ billion lifetime cost for each cohort in revenue loss in taxes and employment insurance premiums (16). Taken together, these findings highlight the importance of welcoming policy researchers to the SPR.

There is also a critical interplay between a child's early development and his or her later health. Dr James Fraser Mustard (1927-2011) (17) proposed that early life experiences shape the health, learning capacity, and social functioning of our children throughout their lives. Dr Mustard spent his career advocating for children and young investigators. He is one of the founding members of McMaster University's Medical School. In the mid-1960s, critical of the medical research funding practices of the Canadian government, he stated, "200 of the 900 medical doctors graduating from Canadian universities each year were heading to the United States due to the lack of research funding in their home country" (17). In addition to advocating for young physician scientists, Dr Mustard called on us to look beyond the hospital for opportunities to improve child health. His call to improve child development was exemplified during the late 1990s when, alongside former New Brunswick Lieutenant Governor Margaret McCain, he co-chaired an influential report for the Government of Ontario highlighting the importance of early childhood education (18). Congruent data from Nobel laureate, Dr James Heckman (19) illustrate the high rate of return for public programs targeting children in their earliest years (Figure 2).

Recent compelling data highlight the important link between early child development and health later in life. Dr Frances Campbell, a Senior Scientist at the Frank Porter Graham Child Development Institute, and colleagues reported the long-term health effects of one of the oldest randomized early childhood interventions, the Carolina Abecedarian Project (ABC Project). While the intervention group had consistently better developmental and education achievements, this team most recently found that disadvantaged children randomly assigned to treatment had a significantly lower prevalence of cardiovascular metabolic disease risk factors in their mid-30s. For example, one in four males in the control group was affected by metabolic

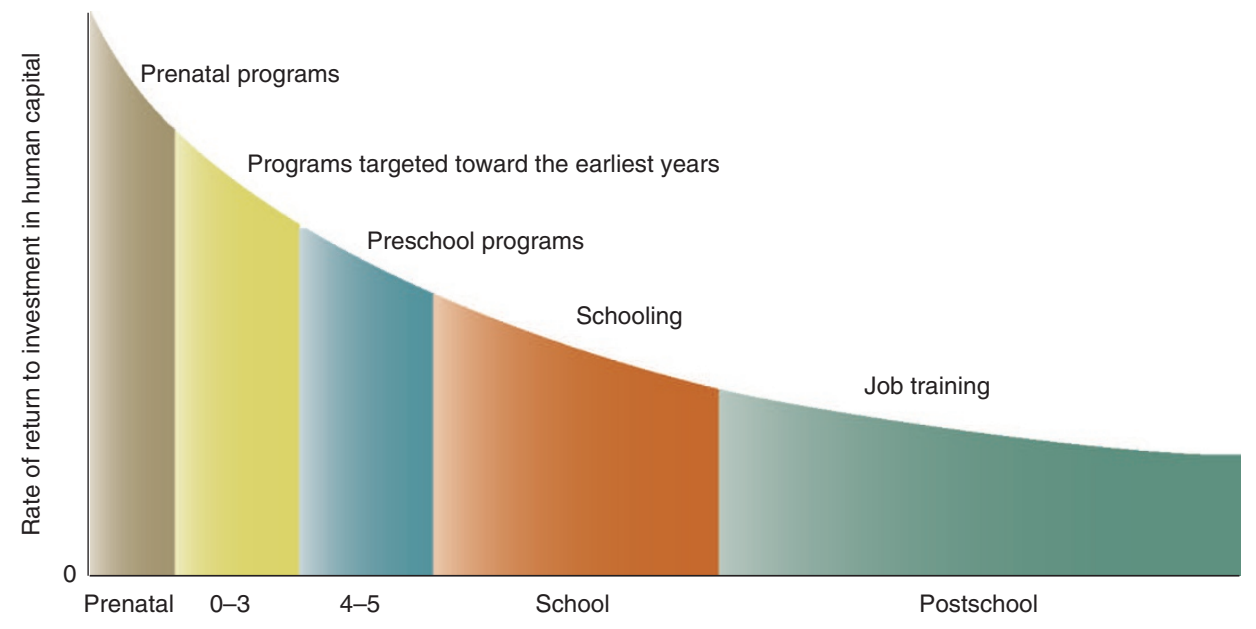

Figure 2. The highest rate of return for public programs is for those that target children in their earliest years. From Heckman (2008), http://www. heckmanequation.org. 
syndrome in contrast with none of the treatment group being affected (20). These data highlight the potential of early life developmental and nutrition interventions for promoting optimal brain health outcomes and preventing adult-onset disease.

As a Canadian completing my term as SPR President and reflecting on this year's Pediatric Academic Societies meeting in Vancouver, it is important that I recognize the memory of Dr Clyde Hertzman (1953-2013), whose early loss has left a profound mark on the child health community in Canada. Clyde inspired a "population sensibility" about children's health and development. In our interactions, he reminded me, and I am sure many others, that caring about children's well-being meant not limiting ourselves to the sickest of the sick. He also effectively advocated that as communities we are all part of an interconnected and interdependent whole. The data collection system he led at the University of British Columbia, the Human Early Learning Project, is one of the strongest population laboratories in the world for understanding children's well-being (19). Through this network, he and his team showed how early development is perhaps the single best measure of the health of a population. This conclusion is well supported by the Campbell (20) study showing how early life interventions can impact longterm health. Dr Hertzman advocated for combining resources and opportunities available to us to support children's welfare, regardless of academic background. It is from his example, and data about how institutions work in interconnected ways for the benefit of children everywhere, that I believe we should welcome epidemiologists addressing child health at a population level, as well as researchers on legal frameworks relevant to child health, and child health policy researchers.

The impressive long-term changes reported by Campbell and colleagues from a randomized trial of early developmental and nutritional intervention leads to the essential question of what has changed in the brains of these children from their early developmental exposures. US President Barack Obama recently announced a "Big Science" initiative focused on the brain: Brain Research through Advancing Innovative Neurotechnologies (BRAIN). President Obama stated eloquently, "As humans, we can identify galaxies light years away, we can study particles smaller than an atom. But we still haven't unlocked the mystery of the three pounds of matter that sits between our ears" (21). The BRAIN "Big Science" initiative follows the successful Human Genome Project, which was estimated to cost $\$ 3.8$ billion and generate nearly $\$ 800$ billion in economic impact, creating more than 300,000 jobs (22). This new presidential initiative focuses our aim on revolutionizing our understanding of the human brain "by accelerating the development and application of novel technologies that will enable researchers to produce dynamic pictures of the brain that reveal how cells and complex neurocircuits interact in time and space" (23). While this initiative is most certainly applauded, we must remember to address the developing brain and to keep child development on the BRAIN and other "Big Science" agendas.

Investing in child health research certainly pays long-term dividends. An example of this was well illustrated by Dr S. Claiborne Johnston, a neurologist and epidemiologist, and colleagues at the University of California, San Francisco, in their review of the economic benefit of the clinical trials portfolio of the National Institute of Neurological Disorders and Stroke (24). Of the 28 trials funded by the institute at a cost of $\$ 335$ million, six trials improved health, with four of these trials resulting in cost savings to society. Almost half of the societal effects in millions of dollars can be attributed to a study of indomethacin for preventing intraventricular hemorrhage in preterm neonates led by SPR Member Dr Laura Ment, a neonatal neurologist at Yale University (25). Investing in child health research makes economic sense.

I hope to have illustrated a gripping case for the growth and progression of the SPR in child health research. I will now turn our attention to supporting our researchers earlier in their career trajectory.

I have personally been very fortunate to have incredible mentors throughout my career and can attest first-hand to the critical importance of mentoring our next generation of child health researchers. "I believe that the decline in research activities among faculty and our failure to attract our best students into careers in academic medicine also stems in part from a lack of bioavailability. In this instance, I refer to the lack of visible and available mentors. Here too we have forgotten many of the important lessons from our past" (26). While these words resonate clearly today, Dr Frank Oski said them in his SPR President's address in 1978. I believe that these words are especially relevant today, 36 years later, as this problem is further compounded by the current fiscal reality.
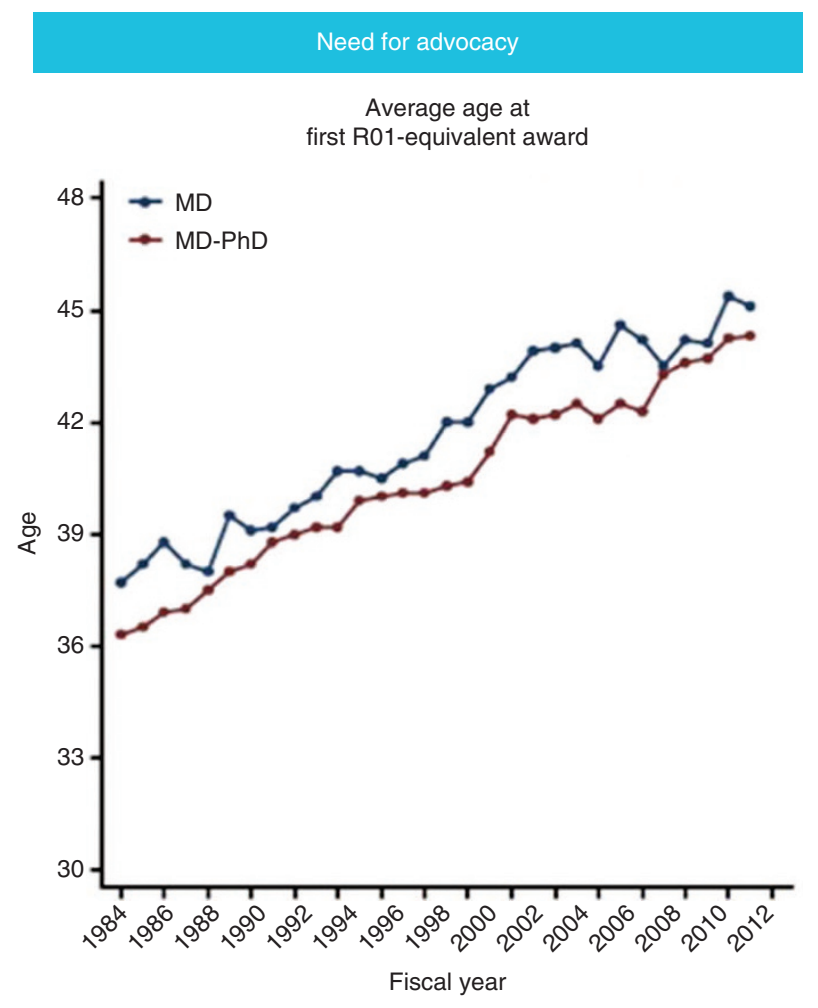

Figure 3. Average age at first R01-equivalent award from the National Institutes of Health (USA) by fiscal year. Image copyright Federation of American Societies for Experimental Biology, http://www.faseb.org. 
Important data from Garrison and Deschamps (27) illustrate concerning trends in the National Institutes of Health appropriations, leading to significantly reduced buying power for our research dollars today. As a society about people, it is particularly concerning for the SPR that research, as the major professional activity of US physicians, has declined dramatically in absolute and relative numbers: in 1984 almost 5\% of US physicians had research listed as a major professional activity, and this is now under $2 \%$ (27). The tendency for US physicians to pursue research appears to be heavily influenced by the National Institutes of Health appropriations. The need for advocacy is only further highlighted by even more concerning data showing that the average age at which an investigator receives a first RO1 increased from $\sim 37$ years to almost 45 years in the period of 1984-2012 (Figure 3) (27). To return to the question originally posed by Dr Oski, "Where have all the mentors gone?" it would appear that so many are still trying to get funding to support their investigator initiated research. As concerning as these fiscal trends appear, they are concurrent with a period of dynamic growth for the SPR, and I remain optimistic that we can continue to support and mentor a robust pipeline of child health researchers.

I have seen an incredible shift in focus away from discussions of the SPR being an honorific society to it being considered an active society committed to improving our support of young child health researchers, over the time I have served on Council. These wonderfully engaged Councils, working through our strategic plan, have led six working groups: communications, mentoring, meeting content, philanthropy and finance, advocacy, and member engagement. A member of Council and a member-at-large lead these groups. Each group fosters the careers of young child health researchers. I am especially grateful to the committee leaders and members and will highlight a few successes:

- Our mentor program is now in its third year with six pairs of mentor-mentees meeting quarterly through the year, with an annual gathering at the Pediatric Academic Societies annual meeting. Feedback from the mentees and their mentors has been phenomenal.

- Our Fellow Section now boasts over 375 members and is fellow-led with oversight from the member engagement committee. Please encourage your trainees to join the SPR so that we bolster the pipeline of child health researchers at its source.

- Most recently, our advocacy committee collaborates closely with the Federation of American Societies for Experimental Biology (FASEB) and other national societies to draw attention to the unique needs of children and the research required to meet these needs.

- Since 2011, our advocacy committee presents the SPR Public Service Award to a national pediatric research advocate. In November 2013, this award was renamed the "Dr. Leona Cutler SPR Public Service Award" in honor of her terrific engagement as co-chair of this committee and representative to the Pediatric Policy Council.
In 2014, this award will be given to Senator Kirsten Gillibrand (D-NY) and Senator Lamar Alexander (R-TN) for their bipartisan co-sponsorship and support of research for preterm neonates.

Even with these successes, the SPR needs your voice to keep child health on the agenda and bolster the pipeline of child health researchers.

Please join the SPR effort: We welcome investigators from all child health disciplines. We bridge basic, clinical, translational, and epidemiological research for the advancement of the health of children worldwide. And we encourage young investigators engaged in research that is of benefit to children. Please consider joining a working group, responding to our calls for advocacy, and, most importantly, mentoring at least one more child health researcher.

The test of our progress is whether we provide enough for those who have too little: We must foster the research and career development of investigators engaged in the health and well-being of children and youth. I am confident that with our collective voice and drive, we, the SPR, are up to the challenge.

\section{ACKNOWLEDGMENTS}

I thank my career mentors for their ongoing encouragement, counsel, and the selfless sharing of their accumulated wisdom: Donna Ferriero, Michael Shevell, and Denis Daneman. In preparing for this address, I am grateful to the many individuals who have taken considerable time to share their perspectives and insights. I extend specific thanks to Michael Salter for sharing his analogy of the brain as a circuit, to Arjumand Siddiqi for her thoughts on the importance of health policy in shaping child health outcomes and on the contributions of Clyde Hertzman, and to Melissa Sundardas for expert editorial assistance.

Finally, and most importantly, I thank my wife, Mina Matsuda-Abedini, and our children for their unwavering support and for instilling this journey with special meaning and fun. S.P.M. holds the Bloorview Children's Hospital Foundation Chair in Paediatric Neuroscience.

\section{REFERENCES}

1. American Pediatric Society/Society for Pediatric Research (APS/SPR). SPR Mission, 2014. (http://www.aps-spr.org/spr/about/missionvision.asp).

2. Brain Canada. NeuroScience Canada Brain Facts, 2014. (http://braincanada.ca/files/NeuroScience_Canada_Brain_Facts.pdf).

3. McKinstry RC, Mathur A, Miller JH, et al. Radial organization of developing preterm human cerebral cortex revealed by non-invasive water diffusion anisotropy MRI. Cereb Cortex 2002;12:1237-43.

4. Vinall J, Grunau RE, Brant R, et al. Slower postnatal growth is associated with delayed cerebral cortical maturation in preterm newborns. Sci Transl Med 2013;5:168ra8.

5. Lipsman N, Woodside DB, Giacobbe P, et al. Subcallosal cingulate deep brain stimulation for treatment-refractory anorexia nervosa: a phase 1 pilot trial. Lancet 2013;381:1361-70.

6. Lipsman N, Sankar T, Downar J, Kennedy SH, Lozano AM, Giacobbe P. Neuromodulation for treatment-refractory major depressive disorder. CMAJ 2014;186:33-9.

7. Papsin BC, Gordon KA. Cochlear implants for children with severe-toprofound hearing loss. N Engl J Med 2007;357:2380-7.

8. Hsu PD, Lander ES, Zhang F. Development and applications of CRISPRCas9 for genome engineering. Cell 2014;157:1262-78.

9. The Science of Early Childhood Development: Closing the Gap Between What We Know and What We Do. Cambridge, Massachusetts: National Scientific Council on the Developing Child, 2007.

10. McCourt C, Paquette D, Pelletier L, Reyes F. Make Every Mother and Child Count: Report on Maternal and Child Health in Canada. Ottawa: Public Health Agency of Canada, 2005. 
11. Siddiqi A, Kawachi I, Berkman L, Subramanian SV, Hertzman C. Variation of socioeconomic gradients in children's developmental health across advanced Capitalist societies: analysis of 22 OECD nations. Int J Health Serv 2007;37:63-87.

12. Hertzman C, Siddiqi A, Hertzman E, et al. Bucking the inequality gradient through early child development. BMJ 2010;340:c468.

13. Risley TR, Hart B. Meaningful Differences in the Everyday Experience of Young American Children. Baltimore: Paul H. Brookes Publishing, 1995.

14. Cunningham AE, Stanovich KE. Early reading acquisition and its relation to reading experience and ability 10 years later. Dev Psychol 1997;33:934-45.

15. Siddiqi A, Kawachi I, Berkman L, Hertzman C, Subramanian SV. Education determines a nation's health, but what determines educational outcomes? A cross-national comparative analysis. J Public Health Policy 2012;33:1-15.

16. Hankivsky O. Cost Estimates of Dropping Out of High School in Canada. Ottawa: Canadian Council on Learning (CCL), 2008.

17. Wikipedia, The Free Encyclopedia. James Fraser Mustard, (2013). (http://en.wikipedia.org/w/index.php?title=James_Fraser_Mustard\&ol $\operatorname{did}=541096713)$.

18. McCain MN, Mustard JF. Early Years Study: Reversing the Real Brain Drain. Toronto: Ontario Children's Secretariat, 1999.

19. The Heckman Equation. Invest in Early Childhood Development: Reduce Deficits, Strengthen the Economy, 2008. (http://heckmanequation.org/ content/resource/invest-early-childhood-development-reduce-deficitsstrengthen-economy).

20. Campbell F, Conti G, Heckman JJ, et al. Early childhood investments substantially boost adult health. Science 2014;343:1478-85.

21. The White House. Remarks by the President on the BRAIN Initiative and American Innovation, 2013. (http://www.whitehouse.gov/ the-press-office/2013/04/02/remarks-president-brain-initiative-andamerican-innovation).

22. Hauser SL, Johnston SC. Big neuroscience. Ann Neurol 2013;73:A5-6.

23. National Institutes of Health (NIH). Brain Research through Advancing Innovative NeurotechnologiesSM (BRAIN), 2013. (http://www.nih.gov/ science/brain/).

24. Johnston SC, Rootenberg JD, Katrak S, Smith WS, Elkins JS. Effect of a US National Institutes of Health programme of clinical trials on public health and costs. Lancet 2006;367:1319-27.

25. Ment LR, Oh W, Ehrenkranz RA, et al. Low-dose indomethacin and prevention of intraventricular hemorrhage: a multicenter randomized trial. Pediatrics 1994;93:543-50.

26. Oski FA. 1978 Presidential Address of the Society for Pediatric Research April 27, 1978. Pediatr Res 1978;12:1145-8.

27. Garrison HH, Deschamps AM. NIH research funding and early career physician scientists: continuing challenges in the $21^{\text {st }}$ century. FASEB J 2014;28:1049-58. 